\title{
Clinico-Pathological Characteristics of Colorectal Cancer among Young Subjects \\ Aged 30 and Under in Tropical Areas: Retrospective Comparative Study \\ Over Ten Years of Clinical Practice in Cameroon
}

\section{Ankouane Andoulo ${ }^{1 *}$, Kowo Mathurin ${ }^{1}$, Atenguena Obalemba Etienne $^{1}$, Ndjitoyap Ndam Antonin William ${ }^{1}$, Bekolo Winnie ${ }^{2}$, Dontsi Donrielle $^{1}$, Eloumou Bagnaka Servais Fiacre ${ }^{2}$}

${ }^{1}$ Department of Internal Medicine and Specialities, Faculty of Medicine and Biomedical Sciences, University of Yaounde I, Yaounde Central Hospital, Cameroon

${ }^{2}$ Department of Clinical Sciences, Faculty of Medicine and Pharmaceutical

Sciences, University of Douala, Douala Gynaecological-Obstetric and Paediatric Hospital, Cameroon

*Corresponding Author: Ankouane Andoulo, Department of Internal Medicine and Specialities, Faculty of Medicine and Biomedical Sciences, University of Yaounde I, Yaounde Central Hospital, Cameroon.
Received: August 17, 2021

Published: August 27, 2021

(C) All rights are reserved by Ankouane

Andoulo., et al.

\section{Abstract}

Introduction: In sub-Saharan Africa, colorectal cancer (CRC) affects nearly 39.2\% of young people aged 20-45 years. Epidemiological data are scarce. The aim was to describe the clinico-pathological characteristics of CRC in young subjects aged 30 years and under. Patients and Methods: Retrospective study, conducted from January 1 to May 15, 2020, on a collection of data from the records of patients who were under patient care for histologically confirmed CRC in the hepato-gastroenterology, digestive surgery and medical oncology departments of ten hospitals in the cities of Yaounde and Douala-Cameroon, from January 1, 2009 to December $31,2019$. Patients were divided into two groups for comparison: the group comprising subjects aged 30 years and under at the time of diagnosis and the group including subjects aged over 30 years.

Results: A total of 153 patients followed for histologically confirmed CRC were included, of which 67 were 30 years old and under (43.8\%) and 86 were older than 30 years (56.2\%). The average age of those 30 years and under was $25.5 \pm 4.2$ years (10 - 30 years). Anaemia (65.7\% vs. 48.8\%; OR: 2.0 [1.0 - 4.1]; p = 0.03), abdominal mass (29.9\% vs. 17.4\%; OR: 2.0 [0.9 - 4.6]; p = 0.07), and occlusive syndrome (16.4\% vs. 7.0\%; OR: 2.6 [0.8 - 8.5]; $\mathrm{p}=0.06$ ) were more prevalent in the 30 years and under group. The general condition was impaired (WHO stage II to IV) in $92.5 \%$ of those 30 years and under (OR: 16.4 [5.6 - 51.7; p < 10 $0^{-5}$ ). Risk factors for CRC were rare in those aged 30 years and under, notably alcoholism (7.5\% vs 43.0\%; OR: 0.1 [0.0 - 0.3]; p < 10-5) and smoking (3.0\% vs 10.5\%; OR: 0.3 [0.0 - 1.4]; $\mathrm{p}=0.06$ ). The average time from symptom onset to diagnosis was $8.6 \pm 4.4$ months for those 30 years and under vs. $9.4 \pm 5.2$ months $\left(\mathrm{p}<10^{-5}\right)$. The left colon was the specific site in those 30 years and under $(16.4 \%$ vs. 4.7\%; OR: 4.0 [1.1 - 16.0 ]; $p=$ 0.03). Ulcerated adenocarcinoma (86.6\%) was more frequent in those aged 30 years and under 43.3\% vs. $27.9 \%$ (OR: 2.0 [1.0 - 4.1 ]; $\mathrm{p}=0.04)$. Well- and moderately-differentiated forms were unfrequently found in patients aged 30 years and under $(19.4 \%$ vs. $34.9 \%$; OR: 0.5 [0.2 - 1.0]; $p=0.03$ and $11.9 \%$ vs. 38.4\%; OR: 0.2 [0.0 - 0.5]; $p<10^{-5}$, respectively). TNM stage II was the most common in both groups. Liver and lung metastases were found approximately equally in both groups.

Conclusion: CRC in young subjects aged 30 years and under is very common in the tropical areas. Some well-known risk factors do not appear too involved. The alteration of the general state seems to be present at the time of diagnosis. Anaemia, abdominal mass and occlusive syndrome are quite common. The left colon is involved in more than $80 \%$ of cases. The adenocarcinoma is ulcerated and of variable differentiation.

Keywords: Colorectal Cancer; Adenocarcinoma; Young Subject; Cameroon 


\section{Introduction}

Colorectal cancer (CRC) develops at the expense of the histological constituents of the colon and rectum [1]. It is a real public health problem worldwide, as it ranks $3^{\text {rd }}$ after breast and prostate cancer [2]. The number of new cases occurring worldwide was estimated in 2018 to be $1,227,000$ and the number of deaths to be 528,500 [3]. The incidence of CRC is geographically variable. For example, data for sub-Saharan Africa show that in 2018, the incidence was 10.7 per 100,000 population for men and 7 per 100,000 population for women for colon cancer. For rectal cancer, it was 5.7 per 100,000 population in men and 3.7 per 100,000 population in women [3]. In sub-Saharan Africa, CRC is the $3^{\text {rd }}$ most common cancer and the $2^{\text {nd }}$ most common cause of death [4]. These data are much higher than those reported in Western countries. Among the subjects with CRC, nearly $39.2 \%$ are between 20 and 45 years of age in sub-Saharan Africa, while the age of occurrence of CRC in developed countries varies between 50 and 75 years [1,4-7].

In Cameroon in 2018, the incidence of CRC was estimated at 7 per 100,000 population in men and 4.5 per 100,000 population in women of all ages [3]. CRC is the sixth most common cancer in Cameroon after breast, cervical, prostate, liver and lymphoma cancers [3].

The endoscopic profile of CRC in the western population aged 30 years and under is represented by a preferential location in the left colon in nearly $70 \%$ of cases and a macroscopic ulcerativebudding aspect [8]. Histologically, it is a moderately differentiated adenocarcinoma in almost $90 \%$ of cases $[9,10]$. The most frequent histological stage is stage III of the TNM classification in almost half of the cases $[9,11]$.

Epidemiological, anatomopathological, diagnosis related and therapeutic data on CRC are scarce in sub-Saharan Africa in general and in Cameroon in particular.

In order to describe the clinical, endoscopic and pathological aspects of CRC in young subjects aged 30 years and under, we conducted a comparative study with a population of subjects over 30 years old.

\section{Materials and Methods}

Retrospective study, conducted from January 1 to May 15, 2020, on a collection of data from the records of patients who were under patient care for histologically confirmed CRC in the hepato-gastroenterology, digestive surgery and medical oncology departments of ten hospitals in the cities of Yaounde and Douala from January 1, 2009 to December 31, 2019.
The patients' records included were those that were complete, i.e. including demographic, clinical, endoscopic and histological data. Once the records were selected, we divided the patients into two groups for comparison: group 1 comprising subjects aged 30 years and under at the time of diagnosis of the condition and group 2 comprising subjects aged over 30 years at the time of diagnosis of the condition.

Demographic data recorded included: age and gender. Risk factors for CRC were: alcoholism, smoking, colonic polyposis, cancer other than CRC, history of CRC, and inflammatory colitis. Clinical data included: circumstances of discovery of CRC, reasons for endoscopy, physical examination data (weight loss, signs of clinical anaemia, palpable abdominal mass, and alteration of general condition according to WHO classification), and time from symptom onset to diagnosis. The results of the endoscopic examination: site of the tumour lesion and macroscopic aspects (infiltrating, ulcerated, ulcero-vegetating, vegetating and stenosing). The extension workup included chest radiography, liver ultrasound, and CT scan. Pathological anatomy data were those collected on surgical specimen: histological type (adenocarcinoma, medullary carcinoma, mucinous carcinoma, kitten ring carcinoma, medullary adenocarcinoma, and squamous cell carcinoma), histological grade (Well differentiated, moderately differentiated, poorly differentiated and undifferentiated), and histological stage according to the TNM classification 2017 ( $8^{\text {th }}$ edition) [8].

\section{Statistical data analysis}

The obtained data were inserted into a data entry mask designed from CS Pro software version 7.1 allowing coding the obtained variables. Subsequently, they were analysed by the software Statistical Package for Social Sciences (SPSS) version 21.0 for Windows (IBM Corp. Released 2011. IBM SPSS Statistics for Windows, version 20.0. Armonk, NY, USA).

The qualitative variables, namely gender, risk factors, circumstances of discovery, signs found on physical examination, endoscopy results and pathology results, were expressed as absolute and relative frequencies.

Quantitative variables such as age and time from symptom onset to diagnosis of CRC were expressed average figures with standard deviations. The comparison between the two independent groups was performed using Student's t-test for averages. Odds ratios (ORs) with their $95 \%$ confidence intervals (CI) were calculated to express the association between the categorical variables.

The tables were designed using Microsoft Word and Microsoft Excel. The significance level of the results was set at $5 \%$. 
Clinico-Pathological Characteristics of Colorectal Cancer among Young Subjects Aged 30 and Under in Tropical Areas: Retrospective Comparative Study Over Ten Years of Clinical Practice in Cameroon

\section{Ethical consideration}

Authorisation $\mathrm{N}^{\circ}$ 989/CIERSH/DM/2020 of the Institutional Committee on Research Ethics for Human Health.

\section{Results}

A total of 153 patients with histologically confirmed CRC were included, of whom 67 patients were 30 years old or younger (43.8\%) and 86 patients were older than 30 years old (56.2\%) with a sex ratio of 1.4 vs 0.9 . The average age of patients aged 30 years and under was $25.5 \pm 4.2$ years ( 10 - 30 years) and that of patients aged over 30 years was $52.0 \pm 12.2$ years (31 - 90 years). Weight loss was the main clinical sign in both groups $(77.9 \%$ vs $72.1 \%$; OR: 1.3 [0.6 - 3.0]; $\mathrm{p}=0.44$ ) followed by anaemia ( $65.7 \%$ vs $48.8 \%$; OR: 2.0 [1.0 - 4.1]; $\mathrm{p}=0.03)$, abdominal pain $(65.7 \%$ vs. $54.7 \%$; OR: 1.6 [0.7 - 3.2]; $\mathrm{p}=0.17$ ) and rectal bleeding (59.7\% vs. $65.1 \%$; OR: 0.8 [0.4 - 1.6]; $p=0.49$ ] in the 30 and under age group. General condition was impaired (WHO stage II-IV) in $92.5 \%$ of those aged 30 years and under vs. $43.0 \%$ of those aged over 30 years (OR: 16.4 [5.6 - 51.7; $<<10^{-5}$ ]. Risk factors for CRC were rare in the 30 and under age group, notably alcoholism (7.5\% vs. 43.0\%; OR: 0.1 [0.0 - 0.3]; $\left.\mathrm{p}<10^{-5}\right)$ and smoking (3.0\% vs. $10.5 \%$; OR: 0.3 [0.0 - 1.4]; $\mathrm{p}=0.06$ ). The time between the onset of symptoms and consultation was $<15$ months for $92.5 \%$ of those aged 30 years and under vs $22.1 \%$ of those aged over 30 years (OR: 43.7 [14.2 - 144.8]; p $<10^{-5}$ ) with an average time between the onset of symptoms and diagnosis of $8.6 \pm 4.4$ months for those aged 30 years and under vs $9.4 \pm 5.2$ months for those aged over 30 years $\left(\mathrm{p}<10^{-5}\right)$ (Table 1$)$.

\begin{tabular}{|c|c|c|c|c|}
\hline Variables & $\begin{array}{l}\text { Subjects } \\
\leq \mathbf{3 0}\end{array}$ & $\begin{array}{c}\text { Subjects > } \\
\mathbf{3 0} \\
\end{array}$ & $\begin{array}{c}\text { OR [IC to } \\
95 \%]\end{array}$ & P Value \\
\hline $\begin{array}{l}\text { Average age } \\
\text { (years) }\end{array}$ & $\begin{array}{c}25,5 \pm 4,8 \\
(10-30)\end{array}$ & $\begin{array}{c}52,0 \pm 12,2 \\
(31-90)\end{array}$ & - & - \\
\hline Gender, n (\%) & & & - & - \\
\hline Males & $39(58,2)$ & $42(48,8)$ & - & - \\
\hline Females & $28(41,8)$ & $44(51,2)$ & - & - \\
\hline \multicolumn{5}{|l|}{$\begin{array}{l}\text { Clinical features, } \\
\text { n (\%) }\end{array}$} \\
\hline Weight loss & $52(77,6)$ & $62(72,1)$ & $1,3[0,6-3,0]$ & 0,44 \\
\hline Rectum bleeding & $40(59,7)$ & $56(65,1)$ & $0,8[0,4-1,6]$ & ] 0,49 \\
\hline Diarrhoea & $17(25,4)$ & $21(24,1)$ & $1,1[0,5-2,3]$ & ] 0,89 \\
\hline Constipation & $29(43,3)$ & $32(37,2)$ & $1,3[0,6-2,6]$ & 0,45 \\
\hline Abdominal pain & $44(65,7)$ & $47(54,7)$ & $1,6[0,7-3,2]$ & ] 0,17 \\
\hline $\begin{array}{l}\text { Occlusive } \\
\text { syndrome }\end{array}$ & $11(16,4)$ & $6(7,0)$ & $2,6[0,8-8,5]$ & ] 0,06 \\
\hline Abdominal mass & $20(29,9)$ & $15(17,4)$ & $2,0[0,9-4,6]$ & ] 0,07 \\
\hline Anaemia & $44(65,7)$ & $42(48,8)$ & $2,0[1,0-4,1]$ & 0,03 \\
\hline AEG WHO 2-4* & $62(92,5)$ & $37(43,0)$ & $\begin{array}{c}16,4[5,6- \\
51,7]\end{array}$ & $<10^{-5}$ \\
\hline
\end{tabular}

\begin{tabular}{|c|c|c|c|c|}
\hline $\begin{array}{l}\text { Risk factors, } n \\
\text { (\%) }\end{array}$ & & & & \\
\hline Alcoholism & $5(7,5)$ & $37(43,0)$ & $0,1[0,0-0,3]$ & $<10^{-5}$ \\
\hline Smoking & $2(3,0)$ & $9(10,5)$ & $0,3[0,0-1,4]$ & 0,06 \\
\hline Colic polyposis & $3(4,5)$ & 0 & - & - \\
\hline $\begin{array}{l}\text { Inflammatory } \\
\text { colitis }\end{array}$ & $1(1,5)$ & $1(1,2)$ & $\begin{array}{c}1,3[0,0- \\
43,1]\end{array}$ & 0,70 \\
\hline CRC history & $6(9,0)$ & $9(10,5)$ & $0,8[0,3-2,8]$ & 0,75 \\
\hline $\begin{array}{l}\text { History of other } \\
\text { cancer }\end{array}$ & $2(3,0)$ & $4(4,7)$ & $0,6[0,0-4,2]$ & 0,46 \\
\hline \multicolumn{5}{|l|}{ Diagnosis time } \\
\hline $\begin{array}{l}<15 \text { months, } \mathrm{n} \\
(\%)\end{array}$ & $62(92,5)$ & $19(22,1)$ & $\begin{array}{c}43,7[14,2- \\
144,8] \\
\end{array}$ & $<10^{-5}$ \\
\hline $\begin{array}{l}\text { Average time } \\
\text { (months) }\end{array}$ & $8,6 \pm 4,4$ & $9,4 \pm 5,2$ & - & $<10^{-5}$ \\
\hline
\end{tabular}

Table 1: Clinical features, risk factors and diagnosis time in subjects of 30 years and under $(n=67)$ and those of 30 years $(\mathrm{n}=86)$ with CRC in Cameroon

*Impairment of general aspect according to WHO, CRC: CRC.

Regarding pathological anatomy, the lower third of the rectum was the main site in both groups $(34.3 \%$ vs $25.3 \%$; OR: 1.5 [0.7 3.1 ] $p=0.29$ ), followed by the left colon in those aged 30 and under (16.4\% vs 4.7\%; OR: 4.0 [1.1 - 16.0]; $\mathrm{p}=0.03$ ) and the right colon in those aged over 30 (7.5\% vs 16.3\%; OR: 0.4 [0.1 - 1.3]; $p=0.10$, for those under 30 ). The main macroscopic aspect was ulcerated in $43.3 \%$ of those aged 30 years and under vs. $27.9 \%$ of those aged 30 years and over (OR: 2.0 [1.0 - 4.1]; $\mathrm{p}=0.04$ ), followed by the stenotic aspect in $29.9 \%$ of those aged 30 years and under vs. $25.6 \%$ of those aged 30 years and over (OR: 1.2 [0.6 - 2.7]; $p=0.56$ ). Adenocarcinoma was the most common histological form in both groups (86.6\% vs. 88.4\%; OR: 0.85 [0.3 - 2.4]; $p=0.74$ ). Well-differentiated and moderately-differentiated forms were less common in the 30 and under age group (19.4\% vs 34.9\%; OR: 0.5 [0.2 - 1.0]; $\mathrm{p}=0.03$ and $11.9 \%$ vs $38.4 \%$; OR: 0.2 [0.0 -0.5$]$; $\mathrm{p}<10^{-5}$, respectively). TNM stage II was the most frequent in both groups $(83.6 \%$ vs $74.1 \%$; OR: 1.8 [0.7 - 4.2]; $\mathrm{p}=0.17$ ). Regarding distant extension, liver and lung metastases were found to be approximately the same in both groups (13.4\% vs. $14.0 \%$; OR: 1.0 [0.3 - 2.7]; $\mathrm{p}=0.92$ and $13.4 \%$ vs. 12.8\%; OR: 1.1 [0.4 - 3.0]; $\mathrm{p}=0.90$, respectively) (Table 2).

\section{Discussion}

Our study shows that the prevalence of CRC in subjects aged 30 years and younger is significant in our geographical environment, accounting for $44 \%$ of all subjects with CRC at the study period. It is recognised that age is a risk factor for CRC in Western countries. For example, in England and Denmark, the average age of on- 
Clinico-Pathological Characteristics of Colorectal Cancer among Young Subjects Aged 30 and Under in Tropical Areas: Retrospective Comparative Study Over Ten Years of Clinical Practice in Cameroon

\begin{tabular}{|c|c|c|c|c|}
\hline Variables & $\begin{array}{c}\text { Subjects } \\
\leq \mathbf{3 0}\end{array}$ & $\begin{array}{c}\text { Subjects } \\
>30\end{array}$ & $\begin{array}{c}\text { OR [IC to } 95 \\
\%]\end{array}$ & $P$ Value \\
\hline \multicolumn{5}{|l|}{ Location, n (\%) } \\
\hline $1 / 3$ lower rectum & $22(34,3)$ & $22(25,3)$ & $1,5[0,7-3,1]$ & 0,29 \\
\hline $\begin{array}{l}1 / 3 \text { medium } \\
\text { rectum }\end{array}$ & $7(10,4)$ & $4(4,7)$ & $2,4[0,6-10,3]$ & 0,14 \\
\hline $1 / 3$ upper rectum & $9(13,4)$ & $11(12,8)$ & $1,1[0,4-3,0]$ & 0,90 \\
\hline Right colon & $5(7,5)$ & $14(16,3)$ & $0,4[0,1-1,3]$ & 0,10 \\
\hline Transversal colon & $2(3,0)$ & $2(2,3)$ & $1,3[0,1-13,3]$ & 0,59 \\
\hline Left colon & $11(16,4)$ & $4(4,7)$ & $4,0[1,1-16,0]$ & 0,03 \\
\hline Sigmoid & $5(7,5)$ & $11(12,8)$ & $0,5[0,2-1,8]$ & 0,28 \\
\hline \multicolumn{5}{|l|}{$\begin{array}{l}\text { Macroscopy, n } \\
(\%)\end{array}$} \\
\hline Ulcerated & $29(43,3)$ & $24(27,9)$ & $2,0[1,0-4,1]$ & 0,04 \\
\hline Infiltrating & $4(6,0)$ & $2(2,3)$ & $2,7[0,4-6,5]$ & 0,61 \\
\hline Vegetating & $2(3,0)$ & $3(3,5)$ & $0,9[0,1-1,6]$ & 0,86 \\
\hline Ulcero-budding & $5(7,5)$ & $8(9,3)$ & $0,8[0,2-2,8]$ & 0,68 \\
\hline Stenosing & $20(29,9)$ & $22(25,6)$ & $1,2[0,6-2,7]$ & 0,56 \\
\hline \multicolumn{5}{|l|}{$\begin{array}{l}\text { Microscopy, n } \\
(\%)\end{array}$} \\
\hline Adenocarcinoma & $58(86,6)$ & $76(88,4)$ & $0,85[0,3-2,4]$ & 0,74 \\
\hline $\begin{array}{l}\text { Mucinous } \\
\text { Carcinoma }\end{array}$ & $8(11,9)$ & $7(8,1)$ & $1,5[0,5-5,0]$ & 0,44 \\
\hline Other type & $(1,5)$ & $3(3,5)$ & $0,4[0,0-4,7]$ & 0,40 \\
\hline \multicolumn{5}{|l|}{ Grade, n (\%) } \\
\hline $\begin{array}{l}\text { Well } \\
\text { differentiated }\end{array}$ & $13(19,4)$ & $30(34,9)$ & $0,5[0,2-1,0]$ & 0,03 \\
\hline $\begin{array}{l}\text { Averagely } \\
\text { differentiated }\end{array}$ & $8(11,9)$ & $33(38,4)$ & $0,2[0,0-0,5]$ & $<10^{-5}$ \\
\hline $\begin{array}{l}\text { Poorly } \\
\text { differentiated }\end{array}$ & $9(13,4)$ & $8(9,3)$ & $1,5[0,5-4,6]$ & 0,42 \\
\hline Not differentiated & $9(13,4)$ & $15(17,4)$ & $0,7[0,3-2,0]$ & 0,50 \\
\hline \multicolumn{5}{|l|}{ TNM stage, n (\%) } \\
\hline $\mathrm{I}$ & $0-$ & $0-$ & - & - \\
\hline II & $56(83,6)$ & $64(74,1)$ & $1,8[0,7-4,2]$ & 0,17 \\
\hline III - IV & $11(16,4)$ & $22(25,9)$ & - & NS \\
\hline \multicolumn{5}{|l|}{$\begin{array}{l}\text { Distance } \\
\text { extension, n (\%) }\end{array}$} \\
\hline Liver Metastasis & $9(13,4)$ & $12(14,0)$ & $1,0[0,3-2,7]$ & 0,92 \\
\hline Lung Metastasis & $9(13,4)$ & $11(12,8)$ & $1,1[0,4-3,0]$ & 0,90 \\
\hline
\end{tabular}

Table 2: Pathologic anatomy features in subjects aged 30 and under $(n=67)$ and in subjects aged $30(n=86)$ with CRC in Cameroon.

set is about 54 years $[1,5,7]$. However, in these countries there is an increase in the incidence of CRC in younger people. Indeed, in 2012 in Cameroon, CRC represented 2.9\% of cancers, which could explain the current high incidence of CRC in young subjects, especially since the general population at the time of the study was predominantly young in the 2010 general population census [12]. This significant proportion of young people with CRC has already been found by other authors, Eu K., et al. in 2004 (43\%) and Changpeng Zhu., et al. in 2015 (28.5\%) [11,13]. Some risk factors such as familial polyposis or history of CRC have been put forward as hypotheses explaining these results $[11,13,14]$. The average onset age for CRC among subjects aged 30 years and under is 25.5 years in our series. This result is not different from the series of Eu k., et al, Sule., et al. and Changpeng., et al. respectively 25 years, 25 years and 26.1 years $[11,13,15]$. The notable difference comes from the extremes of age, as we have a case of 10 years old, for which a history of colonic polyposis and CRC in the family was found. A similar case was already found in Gabon [6]. The sex ratio was in favour of males as often reported in the literature $[13,15]$.

As for risk factors for CRC, we did not find any significantly involved factor in the 30 years old subject as in adults. This finding is also made by other authors $[11,13]$.

Clinically, CRC in the under-30s is significantly represented by signs of anaemia, palpable abdominal mass and occlusive syndrome, which are responsible for a significant alteration of the general condition. This would explain why the time to diagnosis is shorter than in adults, about 8 months instead of 9 months. Intestinal transit disorders such as constipation and diarrhoea do not seem to be more marked in young people under 30 , nor does rectal bleeding.

The distribution of CRC throughout the colon in young people under 30 years is different from that reported for adults [16,17]. Just over $80 \%$ of CRC were found in the left side of the colon, namely the descending colon, sigmoid and rectum. Approximately 58\% of CRC in subjects aged 30 years and under were located in the rectum, with a significant proportion located in the descending colon, compared to subjects aged over 30 years. This result was already found in a previous study in Cameroon [18]. The specific macroscopic aspect was the ulcerated form, found in $43.3 \%$ of cases. This form was already described in our previous series $[19,20]$. This form is followed by the stenosic form, which would explain the occlusive syndrome noted above.

Microscopically, adenocarcinoma, as in adults, is the most common histological type [4,21]. However, whereas subjects over 30 years of age have well and moderately differentiated lesions in the majority of cases, CRC in subjects aged 30 years and under seems to be evenly distributed in the different grades of differentiation. Parietal invasion according to the TNM classification was stage II 
Clinico-Pathological Characteristics of Colorectal Cancer among Young Subjects Aged 30 and Under in Tropical Areas: Retrospective

in both groups, without a significant difference. Similarly, liver and lung metastases were equally present in both groups. The time from symptom onset to management did not seem to affect tumour stage and spread [8].

\section{Conclusion}

CRC in young people of 30 and under is very common in tropical areas. Compared with adults, some known risk factors do not seem to be too involved. Impaired general condition seems to be present at the time of diagnosis, with anaemia, palpable abdominal mass and occlusive syndrome explaining this condition. More than $80 \%$ of the lesions are in the left colon; it appears ulcerated, of variable grade of differentiation. There seems to be no difference in its extension. Further studies will be able to explain the involvement of environmental factors in the occurrence of CRC in young people up to the age of 30 and to clarify the prognosis.

\section{Bibliography}

1. Exarchakou A., et al. "CRC incidence among young adults in England: Trends by anatomical sub-site and deprivation. Manzoli L, éditeur". Plos One 14.12 (2019): 191-194.

2. Belhamidi MS., et al. "Profil épidémiologique et anatomopathologique du cancer colorectal: à propos de 36 cas". The Pan African Medical Journal 30 (2018): 159.

3. Bray F., et al. "Global cancer statistics 2018: GLOBOCAN estimates of incidence and mortality worldwide for 36 cancers in 185 countries". CA: A Cancer Journal for Clinicians 68.6 (2018): 394424.

4. Ouedraogo S., et al. "Épidémiologie, traitement et pronostic du cancer colorectal de l'adulte jeune en milieu sub-saharien”. Bull Cancer 106.11 (2019): 969974.

5. Cai L., et al. "Increasing incidence of CRC in young patients". Ugeskr Laeger 182.1 (2019): 121-198.

6. Diallo Owono FK., et al. "[Epidemiological and diagnostic featurers of CRC in Libreville, Gabon]". Revista da Sociedade Brasileira de Medicina Tropical 71.6 (2011): 605607.

7. Araghi M., et al. "Changes in CRC incidence in seven high-income countries: a population-based study". The Lancet Gastroenterology and Hepatology 4.7 (2019): 511518.

8. Terharr Sive Droste JS., et al. "Does delay in diagnosing CRC in symptomatic patients affect tumor stage and survival? A population-based observational study". BMC Cancer 10 (2010): 332.

9. Al-Barrak J and Gill S. "Presentation and outcomes of patients aged 30 years and younger with CRC: a 20-year retrospective review". Medical Oncology 28.4 (2011):10581061.

10. Hill DA., et al. "Colorectal Carcinoma in Childhood and Adolescence: A Clinicopathological Review". Journal of Clinical Oncology 25.36 (2007): 58085814

11. Zhu C., et al. "Clinicopathological Characteristics of Chinese CRC Patients under 30 Years of Age: Implication in Diagnosis and Therapy". Current Cancer Drug Targets 15.1 (2015): 2734.

12. National Institute of Statistics of Cameroon. "The state and structure of the population: Demographic indicators". Imprimerie Nationale (2010).

13. Eu KW., et al. "CRC in the young: a 12-year review of patients 30 years or less". Colorectal Disease 6.3 (2004): 191194.

14. Lakatos PL and Lakatos L. "Risks for CRC in ulcerative colitis: changes, causes and management strategies". World Journal of Gastroenterology 14.25 (2008): 39473937.

15. Sule AZ and Mandong BM. "Malignant colorectal tumor's in patients 30 years and below: a review of 35 cases". The Central African Journal of Medicine 45.8 (1999).

16. Chang GJ., et al. "Lange Intestine". In: WayLW, Doherty GM, editors. Current surgical diagnosis and treatement. 11th édition. Mc Graw HHI companies (2003): 705-755.

17. Mandong BM and Suie A. "Description of age, sex and site distribution of large bowel cancer in the middle belt in Nigeria". The Nigerian Journal of Surgical Research 5.3-4 (2003): 8084.

18. Ndjitoyap Ndam EC., et al. "Apports de l'endoscopie dans la pathologie digestive basse en milieu Camerounais. Etude analytique de 720 examens". Médecine d'Afrique Noire 38.12 (1991).

19. Ankouane Andoulo F., et al. "Rectal bleeding in adults over 20 years: Endoscopic investigations and results in current hospital practices in Yaoundé, Cameroon". Open Journal of Gastroenterology 39 (2013): 298-302.

20. Ndom P., et al. "Incidence actuelle du cancer et tendance à Yaoundé, Cameroun". Oncology, Gastroenterology and Hepatology Reports 1.1 (2012): 58-63.

21. Rougier P., et al. "Cancer du côlon: épidémiologie, anatomie pathologique, stades de Dukes, physiopathologie, diagnostic, évolution, principes du traitement et prevention". Revue du Praticien 49 (1999): 789793.

\section{Volume 4 Issue 9 September 2021} (C) All rights are reserved by Ankouane Andoulo., et al. 